\title{
Immunohistochemical expression of HepPar 1 in colorectal cancer
}

\author{
Islam A. Jasim* \\ Ameer Dh. Hameedi*
}

\author{
MBChB \\ FICMS (Path)
}

\section{Abstract:}

Background: Colorectal carcinoma is common in Northwest Europe, North America, and other AngloSaxon areas, while it decreases in number in Africa, Asia, and some parts of South America, There are many immunohistochemical markers react to colonic tissue, the large majority of colorectal carcinomas are positive for mucin stains. Colorectal adenocarcinomas are invariably positive for cytokeratin (CK),

Fac Med Baghdad 2017; Vol.59, No.3 Received: Aug. 2017 Accepted: Oct. 2017

Reactivity for CEA is also the rule; as a matter of fact, failure to detect CEA in an adenocarcinoma of makes a colo-rectal site of origin seems to be unlikely, and many other markers that could claimed in colorectal tumors, a one marker that may has a role in staining colorectal tumors is HepPar-1 which is a monoclonal antibody that reacts to an as yet unidentified cytoplasmic marker of normal and neoplastic hepatocytes, which could be expressed in neoplastic or non-neoplastic colorectal tissue.

Objectives: to see the expression of HepPar-1 (cytoplasmic marker of normal and neoplastic hepatocytes) in colorectal cancer.

Patients and methods: Fifty-eight cases (49 with colorectal carcinoma, 9 cases on non-malignant colorectal tissues) male and females depending on records, the study is conducted in GIT specialized hospital in medical city / department of histopathology - Baghdad city during period from 1/10/2016 to 1/4/2017.

Results: cases were studied, the positivity in our study of the cases was (8.2\%), and none of the control "non-neoplastic" cases express this marker. No significant statistical correlation was found between HepPar-1 expression and the tumor grade, site, age or sex, ( $\mathrm{P}$ values $>0.05$ ).

Conclusion: HepPar-1 can be expressed in tumors including $8.2 \%$ of colorectal carcinoma in this study; HepPar-1 is not expressed in normal colorectal tissue.

Keywords: HepPar-1, colonic cancer, rectal cancer, liver secondary tumors

\section{Introduction:}

Carcinoma of the large bowel is common in Northwest Europe, North America, and other AngloSaxon areas, but low in Africa, Asia, and some parts of South America (1). In the United States, it is the third most common cancer among men and women, and the second leading cause of death from cancer. At the same time, it is by far the most curable form of carcinoma of the gastrointestinal tract. Males and females are affected equally. The mean age is 62 years. Cases occurring in the young (40 years of age) are usually located on the distal colon and rectum and tend to show features associated with aggressive behavior, or have one of the hereditary colorectal cancer syndromes (2).

The cause and pathogenesis of colorectal carcinoma are related to both environmental and genetic factors (3).

Specifically, there is a close association between beef consumption, the ingestion of large amounts of animal fat, and the incidence of bowel carcinoma; however, the issue is complex, and the precise nature of the relationship is far from established (4). The genetic factor manifests itself in a variety of ways, the most obvious is the high predisposition for colorectal carcinoma in patients with FAP (Familial adenomatous polyposis) (nearly $100 \%$ by age 50

*Dept. of Pathology, College of Medicine, University islamayad2008@gmail.com years), other forms of polyposis (to a much lesser degree), and in those with the hereditary nonpolyposis colorectal cancer syndrome (Lynch syndrome) and related nonpolyposis associated hereditary conditions (3).

Approximately $50 \%$ of all carcinomas occur in the rectosigmoid area, although their relative incidence seems to be decreasing (5)

The usual malignant tumor of the large bowel is a well-to-moderately differentiated adenocarcinoma secreting variable amounts of mucin.

Other microscopic types are: Mucinous carcinoma, Signet ring carcinoma.

Histochemically, the large majority of colorectal carcinomas are positive for mucin stains. Immunohistochemically, the main mucin protein cores expressed by conventional adenocarcinoma of large bowel are MUC1 and MUC3 (as opposed to MUC2 in mucinous carcinoma) $(6,7)$. Colorectal adenocarcinomas are invariably positive for cytokeratin (CK) (8).

HepPar-1, which is a monoclonal antibody that reacts to an as yet unidentified cytoplasmic marker of normal and neoplastic hepatocytes(9). Because of its good (although not absolute) specificity, it has become one of the most reliable markers of hepatocytic differentiation $(10,11)$. this study is aimed to see expression of this marker in colorectal carcinoma

Patients and methods: 
According to tissue samples the study cases included all cases with colorectal carcinoma of the years 2014, 2015 and 2016 male and females depending on records.

The study is conducted in Gastroenterology and hepatology specialized hospital in medical city / department of histopathology - Baghdad city.

The immunohistochemistry detection kit and antibodies were from the Abcam \& Pathinsitu Companies/ USA. The package came with a dried ice for keeping the antibodies active and usable when arrived they stored in -20 centigrade.

Normal liver tissue was taken as a positive control for Hep-par 1 expression.

Immunohistostaining steps are:

Six micrometer sections were made, Put the section on positive charge, Dewaxing paraffin-embedded sections, Antigen retrieval (EDTA citrate of $\mathrm{PH} 7$ for HepPar-1) was performed, Peroxide block: cover the tissue section with peroxide block solution for 5 minutes, Primary antibody: incubated for 30 minutes, cover the tissue section with PolyExcel polyHRP and incubate for 30 minutes at room temperature, PolyExcel stunnDAB : cover the tissue section with stunnDAB working solution and incubate for 5 minutes at room temperature, Hematoxyline.

\section{Results}

Fifty-eight cases (forty-nine cases of colorectal carcinoma and nine cases of benign and nonneoplastic colorectal biopsies) concerning the immunohistochemical expression of HepPar-1 in colorectal carcinoma; these have been studied in relation to age of the patients, stage of the disease, site of the tumor.

The patients age of colorectal carcinoma ranged from 30-77 years (mean 56.55 years \pm 11.277 ). All of them are well to moderate differentiated adenocarcinoma except one which was poorly differentiated. Three cases $(6.1 \%)$ were well differentiated tumors, 45 cases $(91.8 \%)$ were moderately differentiated tumors.

Twenty four cases $49.0 \%$ were male and twenty five cases $51.0 \%$ were females (table 1), and according to tumor sites; the majority were in sigmoid and rectum 12,16 cases $(24.5 \%, 32.7 \%)$ respectively.

Table 2 explain the positivity of expression of HepPar-1 in males and females and there is no correlation ( $\mathrm{P}$ values $>0.05$ )

Table 3 explain the positivity of expression of HepPar-1 in tumor site (cecum, ascending colon, transverse colon, descending colon, sigmoid, rectum) and there is no correlation ( $\mathrm{P}$ values $>0.05$ ) Table 4 explain the positivity of expression of HepPar-1 in tumor site (above sigmoid colon, rectosigmoid region) and there is no correlation $(\mathrm{P}$ values $>0.05$ )

\begin{tabular}{llll}
\hline Group & & Frequency & Percent \\
\hline Control & Negative & 9 & 100.0 \\
\hline Patient & Positive & 4 & 8.2 \\
\cline { 2 - 4 } & Negative & 45 & 91.8 \\
\cline { 2 - 4 } & Total & 49 & 100.0 \\
\hline
\end{tabular}

Table 2: Gender of cases

\begin{tabular}{llll}
\hline Group & & Frequency & Percent \\
Patient & Male & 24 & 49.0 \\
& Female & 25 & 51.0 \\
& Total & 49 & 100.0 \\
\hline
\end{tabular}

Table 3: Gender * Hep-Par-1 expression

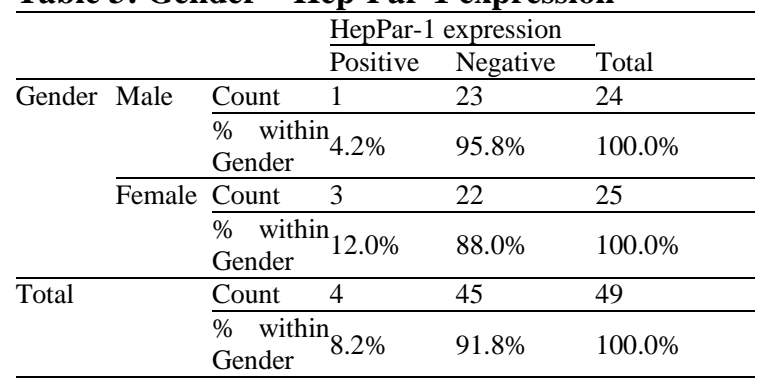

Table 4: Tumor site * Hep-Par-1 expression

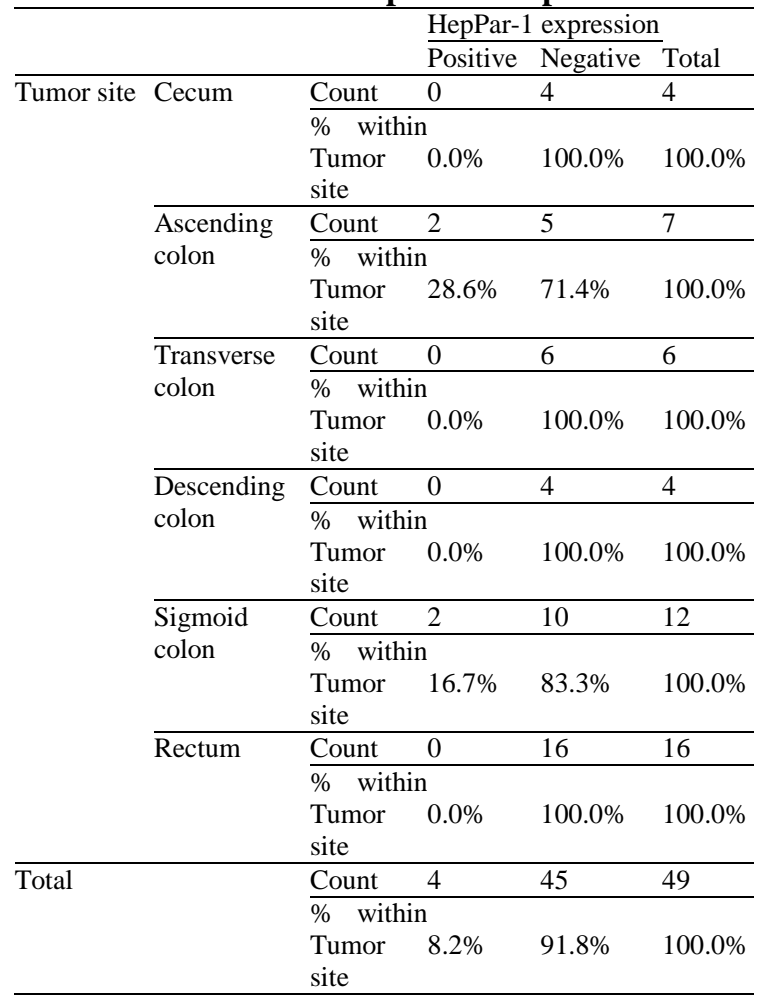

Table 5: Tumor site proximal to sigmoid and rectosigmoid region of Hep-Par-1 expression

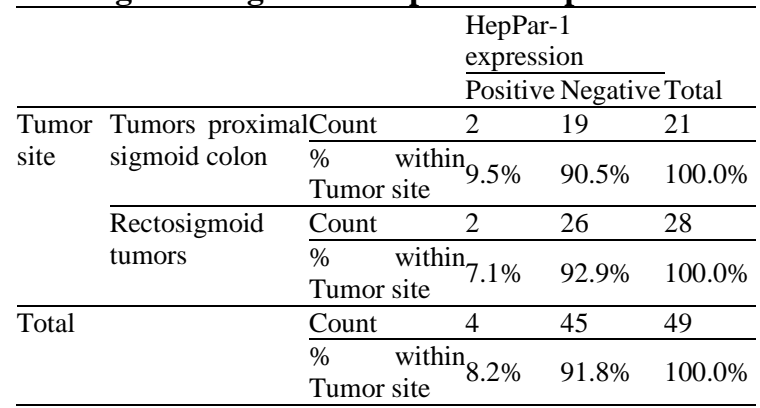

Table 1: Hep-Par-1 expression 


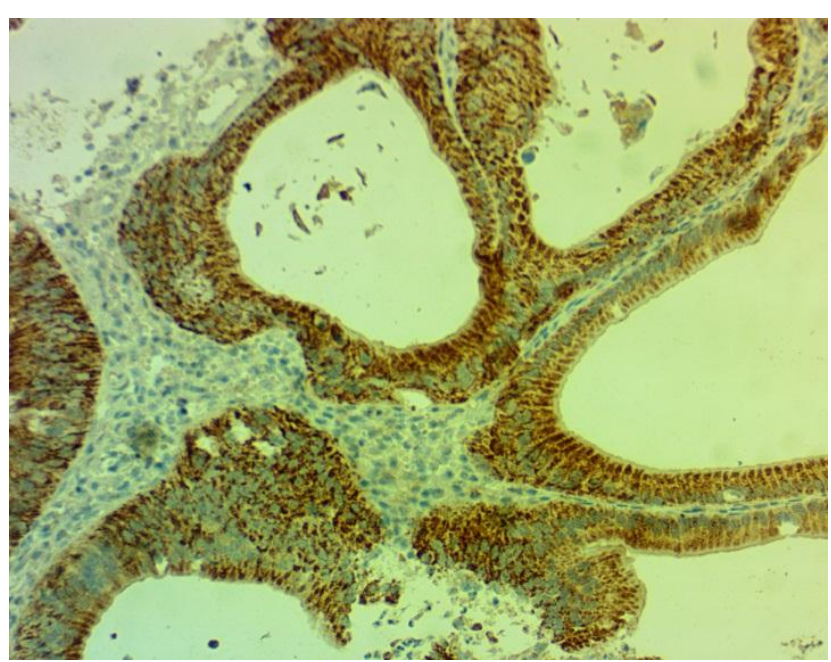

20x focal positivity in colonic cancer with HepPar 1 staining

\section{Discussion:}

HepPar-1 as a marker of hepatocyte differentiation is widely used in the issue of excluding metastatic tumor to the liver in case of single or multiple malignant liver infiltrations. Many studies then tried to assess the expression of Hep-par1 in tumors and tissues of different organs, facts the should be taken seriously when assessing liver lesion. In this study, expression in colorectal carcinoma have been assessed:

Regarding other studies worldwide, this study agreed there are positivity with Villari et al and Fan et al $(12,13)$.

The positivity in our study was $(8.2 \%)$ while in the Villari et al study was (50\%) and agreed with Fan et al study which was $(7.5 \%)$ which is nearly the same as this study. The difference of sensitivity between this study and Villari et al study $(8.2 \%, 50 \%)$ respectively return to that the number of cases in our study are much more than in Villari et al study $(49,9)$ cases respectively In comparison to studies that have explore the expression of HepPar-1 in colonic tissue other than malignancy, the study of Lugli et al (14) showed that $1 / 49(2 \%)$ of high grade dysplasia was positive for HepPar-1 and no case of normal colonic tissue is stained positive.

Other study done by Zimmerman et al (15) states that $(10 \%)$ of colonic tissue was positive, while in this study none of non-neoplastic express this marker. both this study and Zimmerman with his co-workers' study take 10 samples on non-malignant colorectal tissue. The positivity of the tissue (patients and control) was cytoplasmic and no nuclear staining; including this study, Villari et al, Fan et al, Lugli et al. no study that said there is nuclear staining. Other studies of Villari et al, Fan et al, Lugli et al., Zimmerman et al. do not show the parameters like age and gender, in our study; No significant statistical correlation was found between HepPar 1 expression and the age, sex, $(\mathrm{P}$ values $>0.05$ ) Other studies of Villari et al, Fan et al, Lugli et al., Zimmerman et al. did not take other parameters like tumor site and tumor grade, in this study; No significant statistical correlation was found between HepPar 1 expression and the tumor grade, or site ( $\mathrm{P}$ values $>0.05$ )

\section{Conclusions:}

Although HepPar 1 is considered as a marker that defines a normal liver tissue or malignant liver tissue, it can be expressed in other tumors including $8.2 \%$ of colorectal carcinoma in this study.

HepPar 1 is not expressed in normal colorectal tissue.

HepPar 1 is not exclusive marker to liver tissue.

There is no correlation of parameters of the cases (like age, sex, tumor grade, site of the tumor) with the expression of HepPar 1.

\section{Authors' Contributions:}

Dr. Islam Ayad Jasim (M.B.Ch.B.): data collection, study design, manuscripts writing, literature review. Lec. Dr. Ameer Dhahir Hameedi (M.B.Ch.B. , FICMS Path.): Examined all cases (Senior Author)

\section{References:}

1. Center MM, Jemal A, Smith RA, Ward E. Worldwide variations in colorectal cancer. CA: a cancer journal for clinicians. 2009;59(6):366-78.

2. Yantiss RK, Goodarzi M, Zhou XK, Rennert $H$, Pirog EC, Banner BF, et al. Clinical, pathologic, and molecular features of early-onset colorectal carcinoma. The American journal of surgical pathology. 2009;33(4):572-82.

3. Rosai J. Rosai and Ackerman's surgical pathology: Elsevier Health Sciences; 2011.

4. Stemmermann GN, Nomura AM, Heilbrun LK. Dietary fat and the risk of colorectal cancer. Cancer research. 1984;44(10):4633-7.

5. Netscher D, Larson G. Colon cancer. The left to right shift and its implications. Surg Gastroenterol. 1983;2:13-8.

6. Cao Y, Schlag PM, Karsten U. Immunodetection of epithelial mucin (MUC1, MUC3) and mucinassociated glycotopes (TF, Tn, and sialosyl-Tn) in benign and malignant lesions of colonic epithelium: apolar localization corresponds to malignant transformation. Virchows Archiv. 1997;431(3):15966.

7. Zhang H, Maitra A, Tabaczka P, Wilentz $R$, Hruban R, Adsay N, editors. Differential MUCl, MUC2 and MUC5AC expression in colorectal ampullary and pancreatobiliary carcinomas: Potential biologic and diagnostic implications. LABORATORY INVESTIGATION; 2003: LIPPINCOTT WILLIAMS \& WILKINS 530 WALNUT ST, PHILADELPHIA, PA 19106-3621 USA.

8. Chesa PG, Rettig WJ, Melamed MR. Expression of cytokeratins in normal and neoplastic colonic epithelial cells: implications for cellular differentiation and carcinogenesis. The American journal of surgical pathology. 1986;10(12):829-35. 9. Wennerberg AE, Nalesnik MA, Coleman WB. Hepatocyte paraffin 1: a monoclonal antibody that reacts with hepatocytes and can be used for 
differential diagnosis of hepatic tumors. The American journal of pathology. 1993;143(4):1050. 10. Lugli A, Tornillo L, Mirlacher M, Bundi M, Sauter G, Terracciano LM. Hepatocyte paraffin 1 expression in human normal and neoplastic tissues. American journal of clinical pathology. 2004;122(5):721-7.

11. Minervini MI, Demetris AJ, Lee RG, Carr BI, Madariaga J, Nalesnik MA. Utilization of hepatocyte-specific antibody in the immunocytochemical evaluation of liver tumors. Modern pathology: an official journal of the United States and Canadian Academy of Pathology, Inc. 1997;10(7):686-92.

12. Villari D, Caruso R, Grosso M, Vitarelli E, Righi $M$, Barresi G. Hep Par 1 in gastric and bowel carcinomas: an immunohistochemical study. Pathology. 2002;34(5):423-6.
13. Fan Z, van de Rijn M, Montgomery K, Rouse RV. Hep Par 1 Antibody Stain for the Differential Diagnosis of Hepatocellular Carcinoma: 676 Tumors Tested Using Tissue Microarrays and Conventional Tissue Sections. Mod Pathol. 2002;16(2):137-44.

14. Lugli A, Tornillo L, Mirlacher M, Bundi M, Sauter G, Terracciano LM. Hepatocyte Paraffin 1 Expression in Human Normal and Neoplastic TissuesTissue Microarray Analysis on 3,940 Tissue Samples. American Journal of Clinical Pathology. 2004;122(5):721-7.

15.Zimmerman RL, Burke MA, Young NA, Solomides CC, Bibbo M. Diagnostic value of hepatocyte paraffin 1 antibody to discriminate hepatocellular carcinoma from metastatic carcinoma in fine-needle aspiration biopsies of the liver. Cancer Cytopathology. 2001;93(4):288-91. 